\title{
Calidad de vida laboral en un entorno COVID-19. Relación e impacto con respecto al desempeño organizacional
}

\author{
Carlos Santiago-Torner ${ }^{1}$ \\ Universitat de Vic - Universitat Central de Catalunya \\ carlos.santiago@uvic.cat
}

DOI: $\underline{\text { https://doi.org/10.21158/01208160.n91.2021.3050 }}$

Fecha de recepción: 20 de diciembre de 2020

Fecha de aprobación: 11 de agosto de 2021

Fecha de publicación: 30 de octubre de 2021

Cómo citar este artículo: Santiago-Torner, C. (2021). Calidad de vida laboral en un entorno COVID-19. Relación e impacto con respecto al desempeño organizacional. Revista Escuela de Administración de Negocios, (91), páginas. DOI: https://doi.org/10.21158/01208160.n91.2021.3050

\begin{abstract}
Resumen
Esta investigación tuvo como finalidad explorar la relación entre la calidad de vida laboral (CVL) y el desempeño organizacional, en un entorno permeado por el virus SARS-CoV-2, en el marco de una empresa del sector eléctrico colombiano, a través un diseño no experimental, transaccional, correlacional/causal con un enfoque cuantitativo. El análisis permite evidenciar que la organización investigada, a pesar del marco establecido por la pandemia, ha sabido involucrar al colaborador con una mayor autogestión para que su adaptación a las nuevas condiciones laborales de trabajo en casa sea más rápida y cómoda. Además, entre los resultados obtenidos sobresalen los siguientes: se establece una reciprocidad destacada $-r=0,913-$ entre las variables CVL y desempeño, se evidencia que las variaciones profesionales y las disposiciones empresariales iniciadas para enfrentar la alerta de salud mundial refuerzan de forma efectiva la percepción de CVL y los desempeños laborales, de modo que se generan, de forma conjunta, relaciones específicas y sólidas con las dimensiones condiciones laborales, relaciones humanas y participación activa del colaborador frente a situaciones que lo afectan. Finalmente, esta investigación abre el camino a otros estudios vinculados con el desempeño laboral, como, por ejemplo, de qué manera la motivación bajo un entorno de pandemia generada por el COVID-19 se ve afectada e impacta en la productividad y el compromiso organizacionales.
\end{abstract}

Palabras clave: COVID-19; desempeño organizacional; calidad de vida laboral; desempeño laboral; productividad del talento humano; compromiso organizacional.

\footnotetext{
${ }^{1}$ Doctorando internacional en Economía y Empresa - Universitat de Vic - Universitat Central de Catalunya y Universitat de Girona. Magister en liderazgo, gestión del talento y gestión del conocimiento - Universidad Internacional Iberoamericana UNINI, México. Magister en dirección de recursos humanos, comunicación empresarial y corporativa - Universidad Isabel I, España. MBA Sports Management - Escuela de negocios Unisport Management School, España. Especialista en PNL y Coaching - Universidad Isabel I, España. Especialista en selección por competencias - Universidad Tecnológica Nacional UTN, Argentina. Licenciado en gestión de recursos humanos - Universidad Tecnológica Latinoamericana, México. ORCID: https://orcid.org/0000-0002-0852-1578
} 


\title{
Quality of Work Life in a COVID-19 Environment. Relationship and Impact Regarding Organizational Performance
}

\begin{abstract}
The purpose of this research was to explore the relationship between the quality of work life (QWL) and the organizational performance in an environment permeated by the SARS-CoV-2 virus, within the framework of a Colombian company in the electrical sector, through a non-experimental, transactional, correlational/causal design with a quantitative approach. The analysis shows that despite the framework established by the pandemic, the organization under study has involved collaborators with greater self-management so that their adaptation to the new working-at-home conditions is faster and more comfortable. In addition, the following results stand out: outstanding reciprocity is established between the variables $\mathrm{QWL}$ and performance - $\mathrm{r}=$ 0.913 - which shows that the professional variations and the company dispositions that were initiated to face the world health alert effectively reinforce the perception of the QWL and the work performance, so that specific and solid relationships are generated together with the dimensions of working conditions, human relations, and active participation of the collaborators in situations that affect them. Finally, this research opens the way to other studies associated with work performance, such as how motivation is affected and impacts organizational productivity and commitment under a pandemic environment generated by COVID-19.
\end{abstract}

Keywords: COVID-19; organizational performance; quality of work life (QWL); work performance; human talent productivity; organizational commitment.

Qualidade de vida no trabalho em um ambiente de COVID-19.

Relacionamento e impacto com relação ao desempenho organizacional

\section{Resumo}

O objetivo desta pesquisa foi explorar a relação entre a qualidade de vida no trabalho (CVT) e o desempenho organizacional, em um ambiente permeado pelo vírus SARS-CoV-2, no âmbito de uma empresa do setor elétrico colombiano, por meio de um projeto não experimental, transacional, correlacional/causal com uma abordagem quantitativa. A análise mostra que a organização investigada, apesar do quadro estabelecido pela pandemia, tem conseguido envolver o colaborador com maior autogestão para que a sua adaptação às novas condições de trabalho em casa, seja mais rápida e confortável. Além disso, dentre os resultados obtidos, destacam-se: estabelece-se uma reciprocidade destacada $-r=0,913-$ entre as variáveis CVT e desempenho, evidencia-se que as variações profissionais e as disposições empresariais iniciadas para enfrentar o alerta global de saúde reforçam efetivamente a percepção da CVT e o desempenho no trabalho, de forma que relações específicas e sólidas sejam geradas conjuntamente com as dimensões e condições de trabalho, relações humanas e participação ativa do colaborador nas situações que o afeta. Finalmente, esta pesquisa abre caminho para outros estudos relacionados ao desempenho no trabalho, como, de que maneira a motivação em um ambiente pandêmico gerado pela COVID-19 é afetada e como impacta na produtividade e no comprometimento organizacional.

Palavras-chave: COVID-19; desempenho organizacional; qualidade de vida no trabalho; desempenho laboral; produtividade do talento humano; compromisso organizacional. 
Qualité de vie au travail dans un environnement COVID-19.

Relation et impact sur la performance organisationnelle

\section{Résumé}

Le but de cette recherche consiste à explorer la relation entre qualité de vie au travail (QVT) et performance organisationnelle dans un environnement confronté au virus SARS-CoV-2, dans le cadre d'une entreprise du secteur électrique colombien, à travers une conception non expérimentale, transactionnel, corrélationnel/causal, d'approche quantitative. L'analyse montre que l'entreprise étudiée, malgré le cadre contraignant établi par la pandémie, a su impliquer ses collaborateurs en mode d'autogestion pour leur permettre une adaptation rapide et confortable aux nouvelles conditions de télétravail. Les résultats obtenus montrent une réciprocité remarquable $-r=0.913-$ s'établissant entre les variables de QVT et la performance. Ils mettent également en évidence que les variations professionnelles et les dispositions commerciales mises en place pour faire face à la situation sanitaire globale renforcent efficacement la perception de la QVT et la performance au travail de sorte que des relations spécifiques sont crées conjointement aux conditions de travail, aux relations humaines et à la participation active des collaborateurs dans les situations qui les affectent. Enfin, cette étude ouvre la voie à d'autres études liées à la performance au travail, comme par exemple, à la motivation dans un environnement de pandémie généré par le COVID-19, à l'affectation et aux impacts sur la productivité et l'engagement du personnel des organisations.

Mots-clés: COVID-19; performance organisationnelle; qualité de vie au travail; performance du travail; productivité des ressources humaines; engagement organisationnel.

\section{Introducción}

El nuevo escenario de vida, que conlleva una situación inesperada de confinamiento preventivo debido a la crisis sanitaria provocada por el virus SARS-CoV-2, ha llevado a que las organizaciones se planteen cómo optimizar las condiciones laborales del trabajador, que, según Luciano (2016) y Gómez-Rivera (2019), se basan en cuidar tanto las relaciones humanas como el estado y la calidad de la iluminación, los niveles de ruido, la temperatura, el espacio y la ergonomía del lugar de trabajo establecido, de manera que eviten en la situación explorada lo que Pichón-Castillo y Vega-Muñoz (2020) denominan «fusión» de responsabilidades familiares y profesionales que conlleven un desmejoramiento ostensible en la calidad de vida laboral.

Pues, esto, de acuerdo con Lumbreras-Guzmán et al. (2019), repercute en el desempeño organizacional, en la gestión del talento humano, en la estructura y en el ambiente laborales, 
e incide, a su vez, en la productividad y en el compromiso del colaborador como pilares de los resultados esperados a nivel corporativo.

Es importante remarcar, entonces, que el aislamiento, según Hawkley y Capitanio (2015), Goodman-Casanova et al. (2020) y Slimani et al. (2020) puede generar efectos negativos sobre la salud física y la psicológica de las personas a través de emociones dañinas, altos niveles de estrés que supongan un posible deterioro cognitivo, trastornos o interrupción del sueño (Altena et al., 2020) e, incluso, mediante una reducción de la respuesta del sistema inmune.

Cabe destacar que también, mediante la reclusión obligada, se afrontan cambios significativos sociales y culturales al pasar de una modalidad de trabajo $100 \%$ presencial a otra bajo un formato virtual, además desde el propio hogar. De esta manera, afectan todas las situaciones descritas las condiciones laborales, las relaciones humanas y la participación activa del trabajador, que son, según Burke y Deszca (1982), los pilares esenciales de una buena calidad de vida laboral.

Así las cosas, este proyecto de investigación nace con el deseo de relacionar cuantitativamente acontecimientos, al buscarles razón de ser y desarrollar espacios de solución a través del conocimiento de ciertos datos numéricos. En razón a lo anterior, con base en Cadena-Iñiguez et al. (2017), este estudio adquiere una naturaleza cuantitativa, no experimental, transversal y correlacional/causal.

Con relación al alcance espacial se delimita a una organización del sector eléctrico colombiano con sedes en Antioquia y Cundinamarca de una forma integral, pues permea a todas sus áreas de trabajo por igual en busca, además, de encontrar relaciones entre las variables y proponer estrategias de optimización a través de los posibles hallazgos. En cuanto al alcance temporal corresponde al periodo comprendido entre abril y septiembre del 2020.

Al revisar el estado del arte en temas relacionados con calidad de vida y desempeño ante situaciones excepcionales o catastróficas ha sido posible constatar que existen muchos vacíos 
de investigación contrastada, pues la situación de aislamiento físico respecto a los otros miembros de la organización, la cantidad de información diaria para analizar, la reducida viabilidad de utilizar estrategias como, por ejemplo, la actividad física en entornos naturales para calmar la ansiedad o el estrés, la casi imposible desconexión entre familia y trabajo, la propia responsabilidad ante un reto insólito, la sensación de soledad, la posible falta de equilibrio psicológico para evitar que el miedo desborde y la situación salga de control, según Altena et al. (2020) requieren una nueva articulación organizacional diferente a la utilizada hasta el momento, pues el desafío es muy alto y las estrategias para modular respuestas son limitadas. Por esta razón se considera que el proyecto que se desarrollará hará aportaciones teóricas valiosas, ya que explora una situación inédita y agrega nuevo conocimiento.

De la particularidad del entorno al que toda la sociedad está sometida nacen tanto la pregunta de investigación como el objetivo general de este estudio. La pregunta de investigación es: ¿la calidad de vida laboral bajo un entorno COVID-19 ha impactado en el desempeño laboral de los trabajadores de una organización del sector eléctrico colombiano?

El objetivo general de la investigación es examinar la relación y el efecto de la calidad de vida laboral (CVL) sobre el desempeño laboral bajo un contexto por pandemia COVID-19 en una organización del sector eléctrico colombiano.

En cuanto a investigaciones de contraste destacan las que se enumeran a continuación.

a) Lumbreras-Guzmán et al. (2019). En su exploración establecen por medio de un estudio transversal una relación entre calidad de vida laboral y desempeño, pero no es un punto de referencia comparativo con esta investigación.

b) Alarcón-Condori y Astuñague-Gonzales (2018). Es un estudio de corte descriptivo, por lo que los resultados, a pesar de evidenciar relación entre calidad de vida laboral y desempeño, no son comparables con esta investigación. 
c) Herrera-Díaz (2018). Plantea una correspondencia entre calidad de vida y desempeño laboral positiva y moderada de 0,501 a través de la correlación de Pearson. El estudio es cuantitativo.

d) Quinto-Minda (2018). Realiza una exploración documental en la que sí encuentra relación en calidad de vida laboral y desempeño, pero no es útil en esta investigación como contraste.

e) Vallejo-Calderón (2016). Establece una relación entre calidad de vida profesional y el desempeño laboral positiva y baja de 0,383 a través de la correlación de Pearson, pero teniendo en cuenta que no existe un contexto de confinamiento preventivo.

Por último, la estructura de este proyecto de investigación consta de una introducción y un marco teórico compuesto por dos secciones: «Calidad de vida laboral» e «Introducción al desempeño laboral». Así mismo, un marco empírico distribuido en diseño metodológico, resultados, discusión y conclusiones. Se finaliza con un apartado de bibliografía.

\section{Marco teórico}

\subsection{Calidad de vida laboral}

\subsubsection{Condiciones laborales y relaciones humanas.}

La calidad de vida tiene una concepción que involucra muchos aspectos y dimensiones, pero al abordarla en su ámbito laboral es posible tratarla desde el bienestar que proviene del trabajo, el desarrollo personal y profesional, las relaciones humanas e, incluso, la administración del tiempo libre (Aspiazu, 2017; Burke y Deszca, 1982; Jenkins,1983; LeivaGómez, Mansilla-Agüero y Comelin-Fornes, 2017; Murillo-García y Montaño-Ulloa, 2018; Suescún-Carrero, et al., (2016).

Sobre la base de estas consideraciones la empresa motivo de estudio se preocupa por la condiciones laborales de sus colaboradores mediante contratos a término indefinido, un liderazgo horizontal de fácil acceso, unas condiciones de trabajo que priorizan la salud y el 
bienestar familiar, además de planes de carrera internos que enfatizan la proyección profesional del empleado, pues consideran que la satisfacción se relaciona de forma directa con la calidad de vida, pero también tiene como resultado un mayor desempeño y una mayor adhesión empresarial (Bastidas-Herrera y Albarracín-Orellana, 2020; Pedraza-Melo, 2020; Ortega-Valencia, 2020).

De acuerdo con los razonamientos que se han expuesto, la calidad de vida laboral se basa en apreciaciones de satisfacción o insatisfacción (Cruz-Velasco, 2018) que, con miras al contexto creado por la pandemia generada por el COVID-19, es necesario tener en cuenta para estar en capacidad de responder de forma efectiva a las necesidades del empleado con una flexibilización constante de la estructura organizacional que no renuncie al cambio como un ajuste centrado en las personas (de Carrasquel, 2016; Caballero-Pedraza et al., 2017).

En el mismo orden de ideas, es difícil que el ser humano, dentro de su propia naturaleza, viva aislado (Nares-González et al., 2014), por eso la importancia de las relaciones humanas que, según la investigación de Burke y Dezca (1982), centrándose en el ámbito laboral, se fundamentan en la comunicación. Llegados a este punto es sensato preguntarse: ¿cómo la organización motivo de estudio puede cuidar las relaciones humanas dentro de un entorno 100 \% virtual? En relación con la pregunta planteada, Rincón y Zambrano (2008) exponen que la separación física puede generar ciertas inseguridades en las relaciones personales, pues la comunicación no verbal fortalece el mensaje. Además, Cramton, Orvis y Wilson (2007) determinan que la relación virtual puede afectar la adhesión y la satisfacción de los miembros del equipo, de manera que erosionan la confianza entre ellos.

Hecha la observación, teniendo en cuenta los posibles obstáculos, la empresa explorada ha conseguido cuidar las relaciones humanas a través de tareas interdependientes, la comunicación sincrónica de los equipos virtuales y un liderazgo que apoya emocionalmente al trabajador, de modo que esto ayuda en cualquier tipo de adaptación y una realimentación constructiva periódica para evitar la desvinculación del colaborador de la cultura y los objetivos corporativos (Rico, Cohen y Gil, 2006). 


\subsubsection{Participación del colaborador ante situaciones que lo afectan.}

La participación del trabajador dentro de su contexto laboral se asocia con una mayor productividad y motivación desde mediados del siglo pasado (Albalate, 2001; Mayo, 1949). Es evidente, entonces, que la calidad de vida laboral se extiende cuando el colaborador contribuye con su participación al avance organizacional (Quintanilla, 1987; Urcola-Tellería y Urcola-Martiarena, 2017). De este planteamiento se deduce que el modelo actual de dirección necesita que el colaborador tenga un papel protagonista y más si se tienen en cuenta los cambios disruptivos derivados de la pandemia generada por el COVID-19. Además, en el marco de estas consideraciones las empresas maduras utilizan el talento de forma activa, de forma que proporcionan autonomía al empleado con un énfasis especial en la igualdad (Auzero, 2017; Fajardo-García, 2018).

Desde el punto de vista de la propia investigación y teniendo en cuenta a Graţiela-Florentina (2019), ahora más que nunca es necesario que la relación empresa/colaborador se afiance en la confianza, el trabajo en equipo, la participación, la mejora continua, la innovación, la transparencia y un marco de automotivación, autogestión y autocontrol como elementos clave dentro de un contexto de trabajo en casa, de modo que la cooperación sirva para alcanzar un mismo proyecto empresarial.

\subsection{Introducción al desempeño laboral}

El desempeño laboral no deja de ser un reflejo de la capacidad que tiene un individuo de demostrar sus competencias, motivaciones, características personales y valores con la intención de sobresalir en un entorno gobernado por los cambios constantes (Cunha y Corrêa, 2013; Reis-Neto et al., 2020). En ese mismo sentido, autores como Stolovitch y Keeps (1992), Gilley, Dean y Bierema (2001) y Rothwell et al. (2012) asocian desempeño laboral

con logro, resultado que es posible medir, o a una táctica relacionada con las habilidades del colaborador. 
Por su parte, las investigaciones de Fiol y Lyles (1985), Dodgson (1993), Kamoche y Mueller (1998), Easterby-Smith et al. (2000), Williams (2001) y Anderson et al. (2001) suscitan una conexión directa entre desempeño laboral y los índices de productividad y compromiso personales, ya que ambas dimensiones (Pérez-Zapata y Costa-Ramírez, 2009) motivan la fusión entre talento y su retención, junto con la capacidad de incrementar el aporte individual y los resultados vinculados a cada trabajador (Martínez-Pérez, 2005; Shaffer et al., 2001); de esta manera, se articula lo que se conoce con lo que se ignora como una forma implícita de un cambio de comportamiento vinculado a un mejor desempeño laboral.

En un sentido parecido los modelos de conducta con los que se identifican los componentes de la estructura corporativa y los valores implícitos que se entiende son una parte del foro interno de cada individuo, impactan positivamente en el desempeño laboral (Abarbanel et al., 1992; Martínez-Avella, 2010; Cantillo-Padrón, 2013; Davies et al., 2007; Doran, Haddad y Chow, 2004; Schein, 1990; Chenet-Zuta, Arévalo-Quijano y Palma-Alvino, 2017).

Ahora bien, el estudio de Calderón-Hernández, Álvarez-Giraldo y Naranjo-Valencia (2010) avanza un poco más e introduce el concepto de estrategia como ventaja competitiva al vincularla directamente mediante Bird y Beechler (1995) y Hitt et al. (2008) al grado de desempeño, pues la estrategia como pensamiento se fundamenta en las mejores prácticas organizacionales en cuanto fuerza motriz, así como en el talento vinculado a la gestión.

Además, Andrews (1977) determina a la estrategia como básica para establecer objetivos y metas razonablemente alcanzables; más tarde, Munuera-Alemán y Rodríguez-Escudero (2007) definen la estrategia como los actos encaminados a conseguir diferencias que se puedan mantener respecto a la competencia y generen algún tipo de ventaja. Unos años atrás Porter (1980) e investigaciones posteriores (Kotha y Vadlamani, 1995; Powers y Hahn, 2004) vinculan las empresas exitosas con estrategias ordenadas y claras que tienen como objetivo despuntar con un mejor desempeño. 
Por último, Borrero-Caldas, Ossa-Flórez y Tascón-Durán (2008), Cruz-Ortiz, Salanova y Martínez (2013) y Shamir, House y Arthur (1993) asocian diferentes estilos de liderazgo con desempeño laboral, ya que el liderazgo se establece como un proceso activo que contribuye e influencia la motivación, el empoderamiento y las habilidades de los colaboradores, de manera que las orienta hacia la consecución de metas con un óptimo rendimiento (BorreroCaldas et al., 2008; Galarza-Torres, 2019; Elguedas-Hernández, 2017).

\subsection{La productividad y el compromiso laborales}

La investigación de Brito (2020) define a la productividad laboral, en función de VillatoroGarza (2013), como el equilibrio entre el valor de la producción final respecto al costo de los recursos y el capital humano invertidos en ella. García-Can (2018), por su parte, manifiesta que la productividad es fruto de evaluar correctamente los recursos utilizados para obtener un conjunto de resultados y está sujeta a la eficacia, la eficiencia y la efectividad del proceso.

Autores como Daft y Steers (1992), Gelade y Gilbert (2003) y Chiavenato (2010) introducen el término eficacia, el cual puede definirse como alcanzar los objetivos a través de una óptima simetría entre el rendimiento y el consumo, es decir, que el desempeño logrado y el esperado sean objetivamente comparables. Al mismo tiempo, los trabajos de Lockheed y Hanushek (1994), así como los de Cohen y Franco (2000), señalan la eficiencia como la medida en la que se cumplen los propósitos de un proyecto al mínimo costo posible. Por último, Rojas, Jaimes y Valencia (2018), mediante el estudio de Mallo y Merlo (1995), precisan que la efectividad es la manera en la que se mide el grado de consecución de un objetivo.

León-Suárez (2019) establece como nexo una relación significativa entre productividad y compromiso organizacional, de manera que son ambas dimensiones parte del desempeño laboral; por tanto, Díaz-Pendás (2003) menciona que el compromiso organizacional se caracteriza por la afinidad que se genera entre el colaborador y los planes corporativos.

Así mismo, para Jaik-Dipp, Tena-Flores y Villanueva-Gutiérrez (2010) el compromiso se define como la magnitud en que un empleado se alinea con las creencias, los valores y los 
objetivos de una entidad, de modo que buscan, con su esfuerzo, ser una parte activa de esta. De igual forma, Kruse (2013) relaciona compromiso con sentimiento de pertenencia, satisfacción y la nula necesidad de buscar otro puesto de trabajo. Por último, Aldana-Peña (2013) señala que el compromiso predice un buen desempeño, reduce las ausencias laborales y está coordinado con la misión y la visión corporativas.

\section{Diseño metodológico}

\subsection{Diseño de la investigación}

Este estudio está diseñado de forma no experimental, transversal y correlacional/causal, lo cual, según Tejedor-Tejedor (2000), representa la relación entre dos o más variables en un tiempo definido, en busca de, además, la causalidad de la correlación y el sentido de esta. La investigación se apoya en el siguiente objetivo: examinar la relación y el efecto de la calidad de vida laboral (CVL) sobre el desempeño laboral bajo un contexto generado por la pandemia que se dio a causa del COVID-19 en una organización del sector eléctrico colombiano.

\subsection{Variables: operacionalización}

\subsubsection{Calidad de vida laboral como variable independiente.}

De acuerdo con Burke y Deszca (1982), el concepto de calidad de vida laboral es la suma de unas convenientes condiciones laborales, junto con unas adecuadas relaciones humanas, así como permitir al colaborador que sea parte activa de las situaciones que lo afectan y de sus posibles soluciones.

En cuanto a una definición operacional, se trata de examinar, a través de la percepción de los 113 colaboradores de la empresa estudiada, cómo el nuevo contexto laboral ha impactado en las condiciones de trabajo, en las relaciones humanas y en la participación activa del colaborador, a fin de saber si su calidad de vida laboral se ha visto afectada por medio de sus dimensiones. 


\subsubsection{Dimensiones.}

Las dimensiones son:

a) Condiciones laborales y relaciones humanas dentro de la actividad laboral como fuente de una mejor calidad de vida del empleado.

b) Participación del colaborador ante situaciones que le afectan de una forma activa para una mejor calidad de vida en el marco laboral.

\subsubsection{Desempeño laboral como variable dependiente.}

El desempeño laboral, como concepto, es la eficacia y la aptitud del trabajador en su ámbito profesional y su afinidad con una óptima productividad, junto con un arraigado compromiso personal, que puedan ser útiles para alcanzar los objetivos organizacionales (GómezCórdova, 2019; Soto-Rodríguez, 2019).

En cuanto a su definición operacional, se trata de examinar a través de la percepción de los 113 colaboradores de la empresa objeto de estudio si el nuevo contexto de trabajo ha afectado sus niveles de productividad y compromiso como dimensiones de la variable desempeño laboral.

\subsubsection{Dimensiones.}

Las dimensiones son:

a) La productividad como uso eficiente de recursos mediante la equilibrada relación entre resultados y el tiempo que toma conseguirlos.

b) El compromiso laboral como la respuesta afectiva del empleado con respecto al conglomerado organizacional, junto con la afiliación a sus metas y valores. 


\subsection{Enfoque de la investigación}

El enfoque de este estudio ha sido cuantitativo, el cual, según Alonso, Volkens y Gómez (2012), es aquel que se fundamenta en bases numéricas para examinar y demostrar una información, especificando la asociación y la fuerza entre dos o más variables.

\subsection{Población, muestra y muestreo}

En este estudio población y muestra coinciden, pues las 113 personas vinculadas a la organización del sector eléctrico motivo de estudio han participado, de manera que se cumplen todos los principios de inclusión, que en esta investigación se fundamentan en que el empleado lleve más de seis meses dentro de la organización y trabaje de forma virtual.

En este proyecto de investigación la población se estableció de la siguiente forma: 53 mujeres y 70 hombres, por rangos de edad entre 18 y 24 años, tres personas pertenecientes al género femenino y tres al masculino; entre 25 y 34 años, 25 mujeres y 34 hombres; en el rango de 35 a 44 años, 21 personas pertenecientes al sexo femenino y 14 al masculino; dentro del rango de 45 a 54 años, dos mujeres y seis hombres; entre 55 y 64 años, dos personas del sexo femenino y una del masculino; para terminar, entre los mayores de 65 años dos hombres.

A nivel de estudios cabe destacar que de las personas que constituyeron la muestra una era bachiller, diez técnicos, dieciocho tecnólogos, cuarenta y ocho profesionales, veintitrés especialistas, doce con estudios de maestría y una persona con doctorado. La población se constituyó en un censo para todos aquellos individuos que conformaban la empresa motivo de estudio, ya que el $100 \%$ de las personas aceptaron participar.

\subsection{Técnicas e instrumentos de recolección}

Este estudio utilizó como técnica la encuesta tipo web mediante un cuestionario de 102 preguntas que actuó como instrumento de recogida de información, de modo que es, además, sincrónica. Así mismo, en el cuestionario se utilizó la escala Likert que, según Fabila-Echauri, Minami e Izquierdo-Sandoval, (2012), recaba el criterio sobre un tema concreto, 
normalmente, a través de cinco grados que van de totalmente en desacuerdo a totalmente de acuerdo.

La validación del contenido del instrumento de recolección se realizó mediante el juicio de dos expertos ya que, según Galicia-Alarcón et al. (2017), la claridad en la redacción, la coherencia interna, el sesgo o la inducción a la respuesta, el lenguaje adecuado con el suficiente nivel de información y la forma de medir son las características principales para dar validez a una encuesta para su consiguiente aplicación.

Respecto a la confiabilidad, el instrumento utilizado en el artículo se ha validado con el coeficiente alfa de Cronbach, lográndose un 0,952 que es una excelente fiabilidad, según Ventura-León (2019).

\subsection{Técnicas y procesos de datos}

Los datos fueron procesados a través del programa SPSS (Statistical Package for Social Science) versión 25, el cual facilita crear archivos y bases de datos de una forma estructurada para que sea posible analizarlos con diversas técnicas estadísticas básicas y avanzadas. Las técnicas utilizadas en este trabajo de investigación para procesar los datos han sido la estadística descriptiva que Bogdan y Taylor (1990) definen como las técnicas que involucran la búsqueda y la exactitud de un grupo de datos con el objetivo de presentar de una forma adecuada sus peculiaridades, de modo que puedan así comparar.

Conjuntamente con la estadística inferencial que Cadena-Iñiguez et al. (2017) manifiestan se enfoca en la toma de decisiones o la realización de generalidades, acerca de las tipologías de todos los análisis realizados, considerando información parcial o incompleta. El mismo autor acota un poco más la definición anterior y señala que esta rama de la estadística infiere y concluye a partir de una muestra del conjunto, ya que su papel es interpretar, relacionar, hacer proyecciones y comparar. 
En este estudio se han utilizado el coeficiente de correlación de Pearson - que es un índice que mide el valor de covariación entre distintas variables conexas de forma lineal-y el modelo de regresión lineal, en el que la estimación de la variable respuesta — dependientese establece mediante la variable predictora —independiente- (véase la Tabla 1).

Tabla 1. Criterio establecido para agrupar los resultados — proceso de datos-

\begin{tabular}{|c|c|c|}
\hline \multirow{2}{*}{ Muy débil } & $80 \%-1$ punto & \multirow{9}{*}{$\begin{array}{l}\text { Objetivo: evitar que un \% de respuestas } \\
\text { reducido con alta o baja puntuación } \\
\text { oculte la tendencia. }\end{array}$} \\
\hline & $20 \%-5$ puntos & \\
\hline \multirow{2}{*}{ Débil } & $80 \%-2$ puntos & \\
\hline & $20 \%-5$ puntos & \\
\hline \multirow{2}{*}{ Aceptable } & $80 \%-4$ puntos & \\
\hline & $20 \%-1$ punto & \\
\hline \multirow{2}{*}{ Fuerte } & $80 \%-5$ puntos & \\
\hline & $20 \%-1$ punto & \\
\hline Muy fuerte & $+80 \%-5$ puntos & \\
\hline
\end{tabular}

Fuente. Elaboración propia.

\section{Resultados}

En cuanto al estudio de los resultados tanto en la variable Calidad de vida laboral como en la variable Desempeño organizacional, ambas variables y todas sus dimensiones tienen una distribución normal, según la prueba de Kolmogorov-Smirnov, con una significancia entre 0,190 y 0,200; por tanto, es posible utilizar estadística paramétrica.

En busca de dar respuesta tanto al problema propuesto como al objetivo general, que es explorar la relación y el impacto de la calidad de vida laboral, bajo un contexto COVID-19, en el desempeño laboral de una empresa del sector eléctrico colombiano, la investigación pretende, inicialmente, entender la percepción de los colaboradores de ambas variables con los siguientes resultados.

En las dos variables estudiadas, el $100 \%$ de los encuestados consideran que tanto su calidad de vida laboral como su desempeño laboral son, como mínimo, aceptables. Cabe destacar que 
el 97,34 \% - 110 personas - percibe tener una calidad de vida laboral fuerte o muy fuerte, y que el 95,57 \% - 108 personas - tiene una autopercepción de desempeño fuerte o muy fuerte (véase la Figura 1).

Figura 1. Comparación entre CVL y desempeño

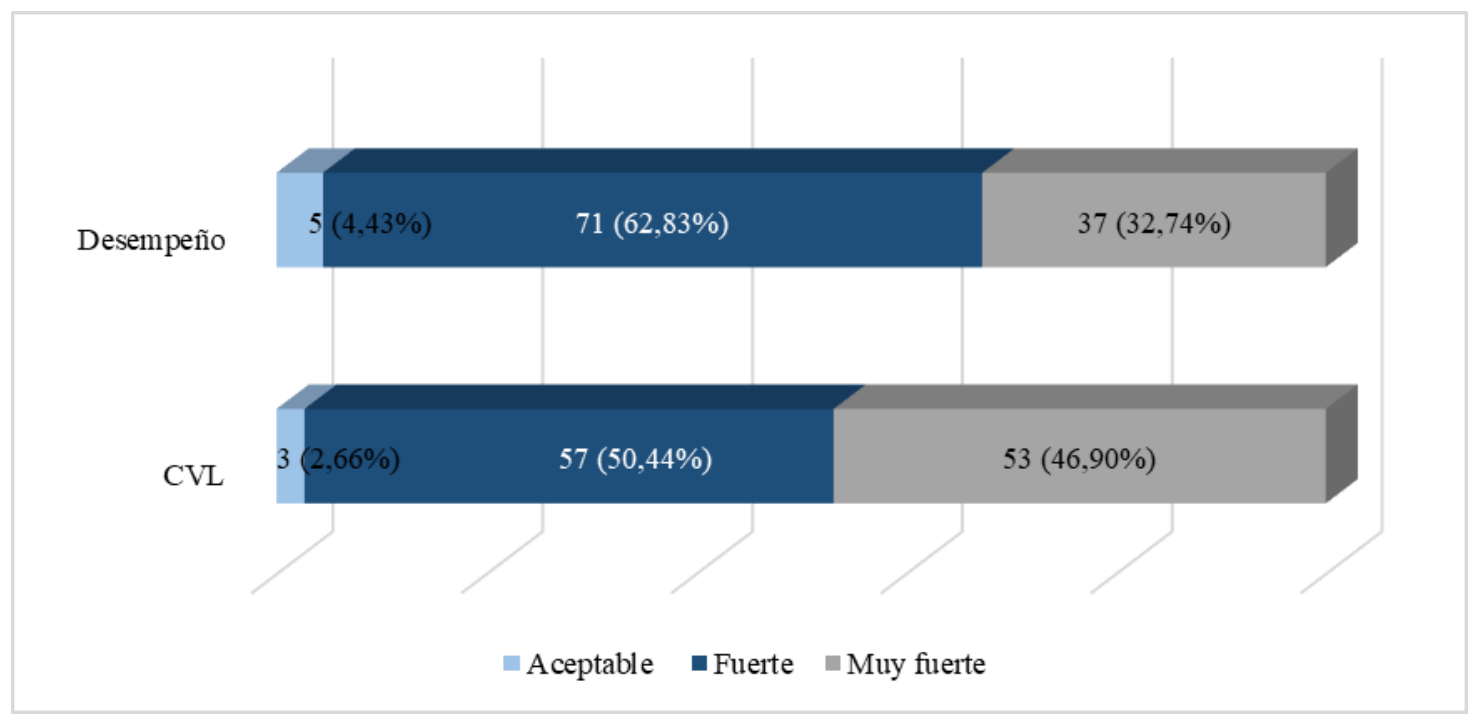

Fuente. Elaboración propia.

\subsection{Calidad de vida laboral}

\subsubsection{Condiciones laborales y relaciones humanas.}

\subsubsection{Condiciones laborales.}

Referente a las condiciones laborales trabajando desde casa, es decir, el acompañamiento empresarial, la iluminación, la temperatura, el confort, la ventilación y los niveles ruido el 95 \% - 107 personas - de los encuestados está conforme o muy conforme.

Con respecto a la conciliación entre vida familiar y laboral, el tiempo libre, la comunicación con los miembros del hogar, la disminución de gastos y el aumento en la calidad de vida trabajando desde casa, el 92 \% -104 personas- de los que participaron en la exploración 
está satisfecho o muy satisfecho. Además, el $99 \%$-112- personas se siente más seguro frente a un posible contagio trabajando desde casa.

\subsubsection{Relaciones humanas.}

En cuanto al apoyo y el acompañamiento del equipo de trabajo, la realización profesional, el nivel y la calidad de comunicación con el resto de los colaboradores, el apoyo emocional del liderazgo y la relación horizontal, además del desarrollo de creatividad e innovación como herramientas para mejorar los puntos de unión corporativa, el 95 \% -107 personas- está complacido o muy complacido.

4.1.2 Participación del colaborador ante situaciones que le afectan.

Con relación a este indicador, el colaborador se ha sentido implicado en la respuesta institucional respecto a la pandemia generada por el COVID-19; está alineado con la cultura corporativa y las decisiones empresariales, así como siente transparencia en la información recibida en un $99 \%-112$ personas-.

\subsection{Desempeño laboral}

\subsubsection{Productividad.}

Respecto a este indicador las personas que han participado en esta exploración se sienten satisfechas o muy satisfechas en un 97 \% -110 personas-con la definición de actividades y tareas, la realimentación individual, el clima organizacional y el aporte personal al logro de objetivos. Además, el 73 \% considera que su productividad ha aumentado trabajando desde casa. 


\subsubsection{Compromiso.}

La adhesión respecto a la organización motivo de estudio es fuerte o muy fuerte en un 95 \% -107 personas-, pues estas se sienten plenamente realizadas, consideran el liderazgo como un punto de anclaje para su desarrollo y confían en la resiliencia y la capacidad de adaptación organizacional, además de creer que no existe discriminación por género en las promociones internas o el trato personal con los demás miembros. Conjuntamente, el 75 \% está seguro de que su motivación es mayor desde que trabajan en el hogar.

\subsection{Relación entre calidad de vida laboral y desempeño}

\subsubsection{Correlaciones de Pearson calidad de vida laboral y desempeño}

\subsubsection{Condiciones laborales y relaciones humanas y desempeño laboral.}

En un contexto de pandemia generada por el COVID-19 se encuentra que existe una fuerte correlación $-r=0,892$ - entre las condiciones laborales y las relaciones humanas respecto al desempeño laboral. Esto quiere decir que conociendo la variable dimensión 1 podemos predecir el resultado del desempeño laboral en un $80 \%$, pues el resultado de $R^{2}=0,799$ no proporciona un poder explicativo alto del ajuste entre ambas variables, además del grado de confiabilidad del pronóstico. 
Figura 2. Correlación de Pearson primera dimensión calidad de vida y desempeño

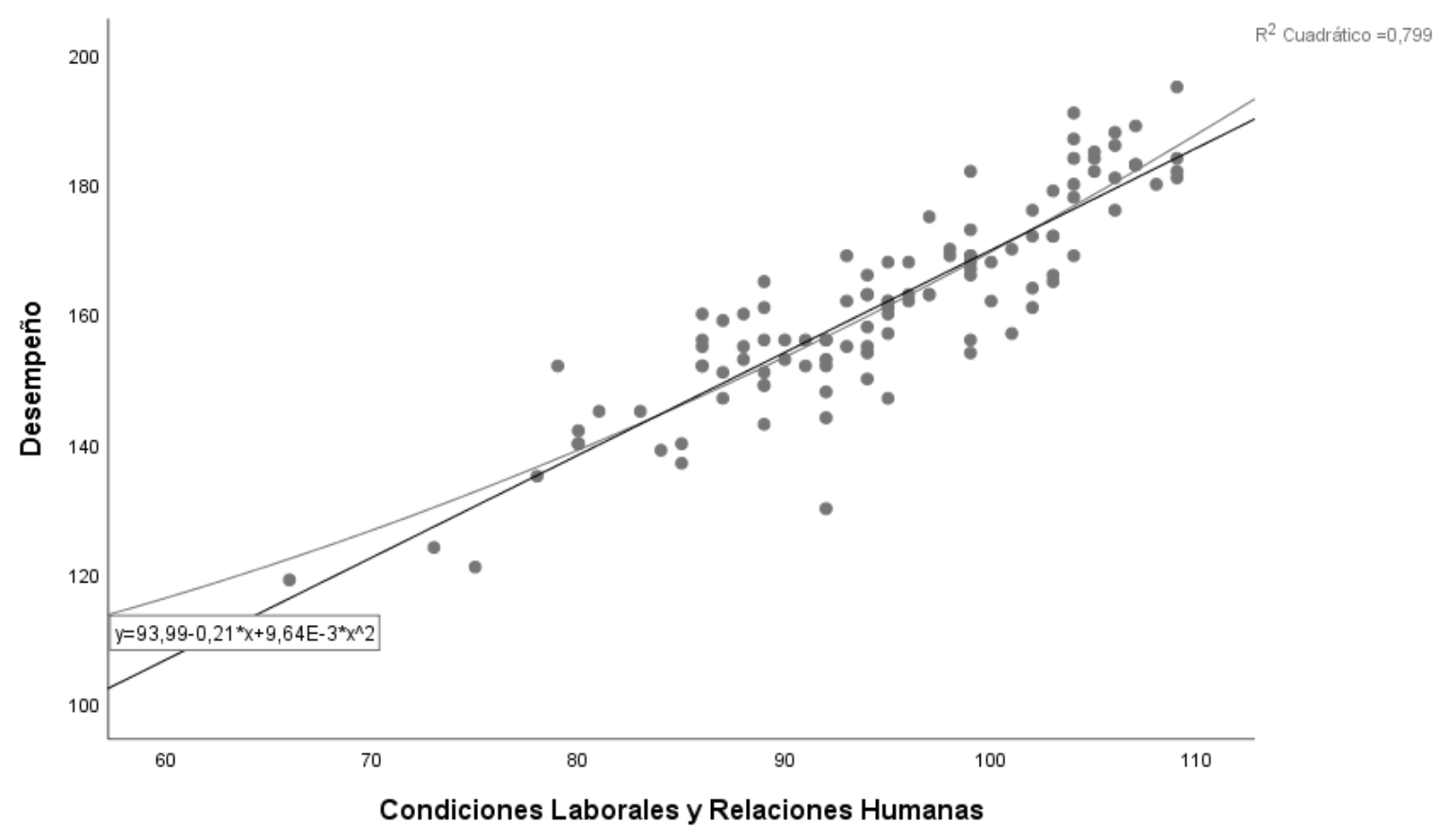

Fuente. Elaboración propia.

4.3.2.2 Participación del colaborador ante situaciones que le afectan de una forma activa y Desempeño laboral.

En un contexto de pandemia generada por el COVID-19 se encuentra que existe una moderada correlación $-r=0,631$-entre la participación activa del colaborador en la toma de decisiones que lo afecten respecto al desempeño laboral. Eso quiere decir que conociendo la variable dimensión 2 podemos predecir el resultado del desempeño laboral en un $40 \%$, pues el resultado de $R^{2}=0,399$ no da un poder explicativo moderado del ajuste entre ambas variables, además del grado de confiabilidad del pronóstico. 
Figura 3. Correlación de Pearson segunda dimensión calidad de vida y desempeño

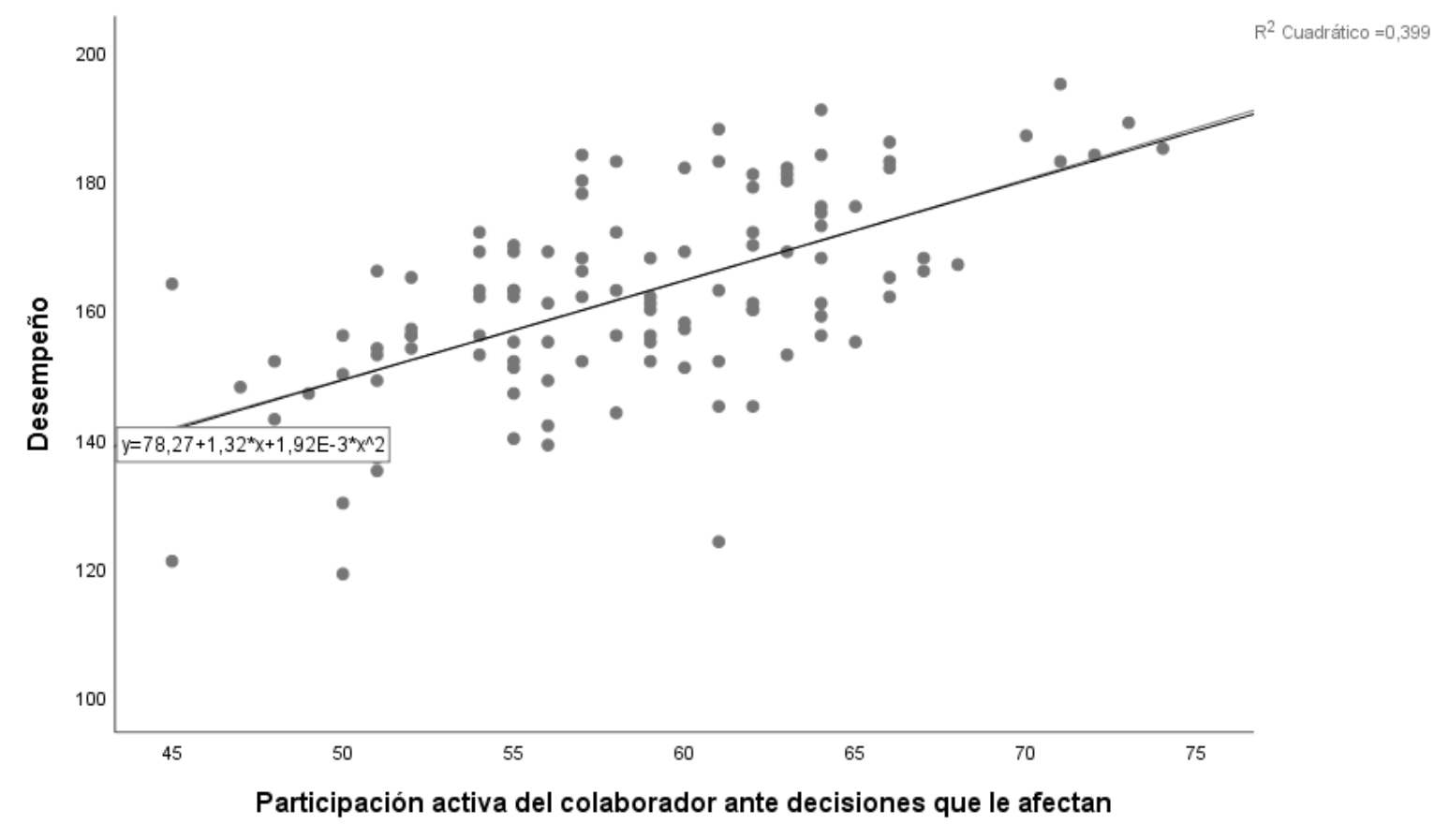

Fuente. Elaboración propia.

\subsubsection{Calidad de vida laboral y desempeño laboral.}

En un contexto de pandemia generada por el COVID-19 se encuentra que existe una muy fuerte correlación $-r=0,913-$ entre la calidad de vida laboral respecto al desempeño. Esto quiere decir que conociendo la variable completa calidad de vida laboral podemos predecir el resultado del desempeño laboral en un $83 \%$, pues el resultado de $R^{2}=0,834$ no brinda un poder explicativo alto del ajuste entre ambas variables, además del grado de confiabilidad del pronóstico. 
Figura 4. Correlación de Pearson calidad de vida laboral y desempeño

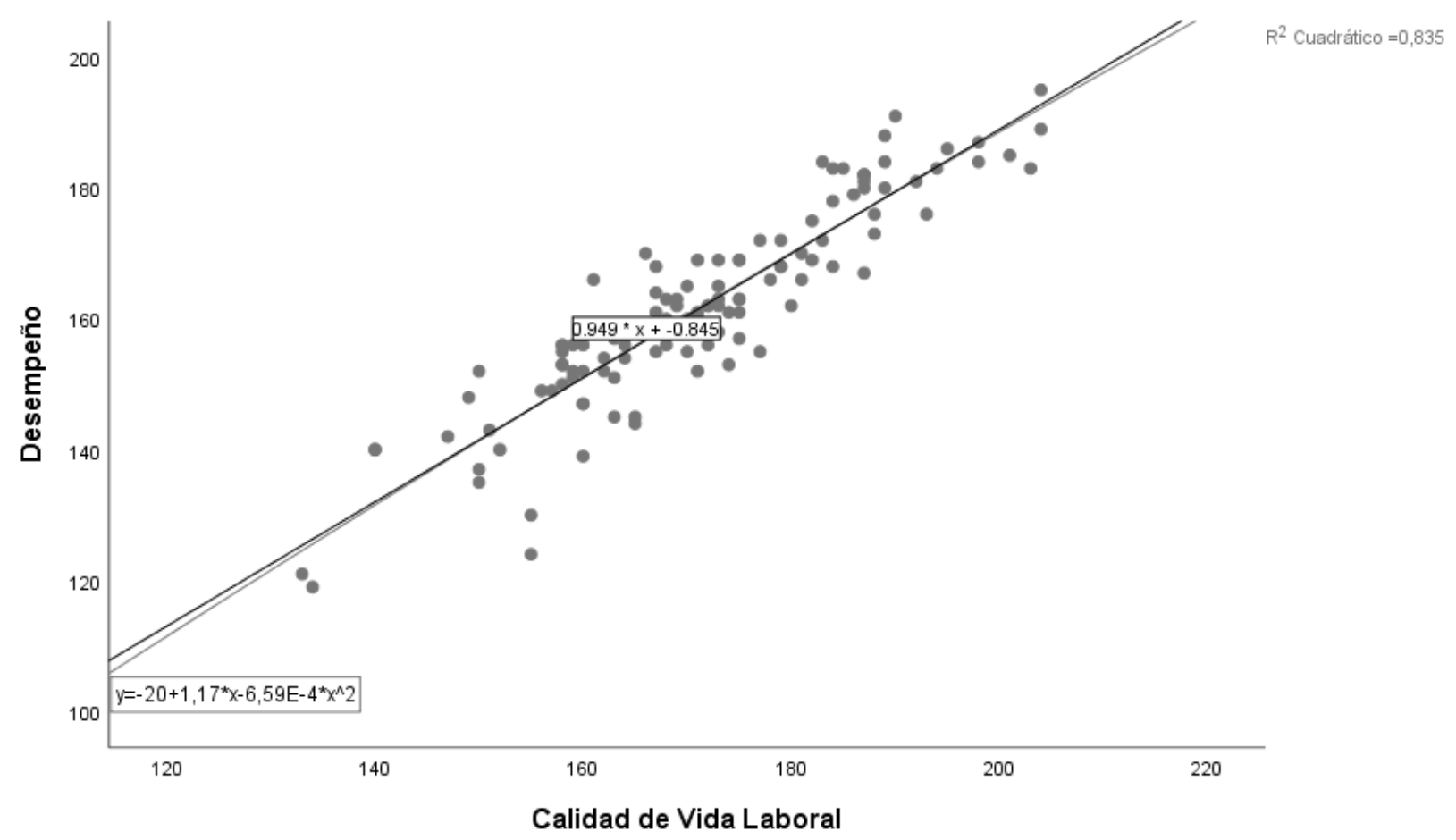

Fuente. Elaboración propia.

Los resultados indican que dentro de un marco permeado por constantes e impredecibles cambios inducidos por la pandemia generada por el COVID-19 se establecen fuertes asociaciones entre la variable independiente — calidad de vida - y la dependiente desempeño laboral-. En este mismo sentido se obtiene una alta confiabilidad, a través de la regresión lineal, a la hora de predecir el resultado del desempeño laboral, de modo que se conoce tanto las dimensiones independientes como la variable completa calidad de vida laboral, pues se obtienen buenos grados de ajuste (véase la Tabla 2). 
Tabla 2. Resultados correlación de Pearson variables calidad de vida laboral y desempeño laboral

\begin{tabular}{|c|c|c|c|c|c|}
\hline & $\mathbf{R}^{\mathbf{1}}$ & Sig.2 & $\mathbf{R}^{3}$ & Grado de ajuste 4 & Sin explicar 5 \\
\hline $\begin{array}{l}\text { Condiciones laborales y } \\
\text { relaciones humanas }\end{array}$ & 0,892 & 0,000 & 0,795 & $80 \%$ & $20 \%$ \\
\hline $\begin{array}{l}\text { Participación del empleado } \\
\text { ante situaciones que lo } \\
\text { afectan }\end{array}$ & 0,631 & 0,000 & 0,398 & $40 \%$ & $60 \%$ \\
\hline Calidad de vida completa & 0,913 & 0,000 & 0,834 & $83 \%$ & $17 \%$ \\
\hline \multicolumn{6}{|c|}{$\begin{array}{l}\text { Nota: }{ }^{1} \text { correlación de Pearson; }{ }^{2} \text { significación bilateral; }{ }^{3} \text { correlación de Pearson al } 2 \text { a través del modelo de regresión lineal; }{ }^{4} \\
\text { grado de ajuste o determinación entre dimensiones o variables; }{ }^{5} \text { elementos sin explicar }-1 \text {-x- siendo x los elementos } \\
\text { compartidos. A este valor se le denomina coeficiente de no determinación o coeficiente de alienación y se define } 21 \text { xy-r. }\end{array}$} \\
\hline \multicolumn{6}{|c|}{$\begin{array}{l}\text { Nota específica: se utiliza la correlación de Pearson para encontrar la asociación, y la fuerza de esta entre la variable } \\
\text { independiente calidad de vida y la dependiente desempeño laboral, mientras que se usa la regresión lineal para describir cómo } \\
\text { la variable independiente está relacionada en el nivel numérico con la dependiente, estableciéndose, de esta forma, una relación } \\
\text { funcional entre ambas variables que permita realizar planificaciones posteriores sobre posibles escenarios y sucesos. }\end{array}$} \\
\hline
\end{tabular}

Fuente. Elaboración propia.

\section{Discusión y conclusiones}

En respuesta a la pregunta de investigación, ¿la calidad de vida laboral bajo un entorno COVID-19 ha impactado en el desempeño laboral de los trabajadores de una organización del sector eléctrico colombiano?, tras esta investigación se sabe que el $100 \%$ - 113 - de las personas encuestadas considera que su calidad de vida laboral, como mínimo, es aceptable, y en más del 97 \% -110 personas- ese índice llega a ser fuerte o muy fuerte. Al mismo tiempo, el $100 \%$ - 113 personas- de las personas que han participado en este estudio estiman que su desempeño es al menos aceptable, y en casi un $96 \%$ - 108 personas- esa consideración es fuerte o muy fuerte; además, el $75 \%$-82 personas- asegura que el contexto de la pandemia generada por el COVID-19 ha incrementado su motivación organizacional; el 73 \% -85 personas - cree que la situación generada por el COVID-19 ha aumentado su desempeño y productividad laborales, y el $88 \%$ - 99 personas- que la repuesta de la organización motivo de estudio frente a esta pandemia COVID-19 ha ampliado su nivel de adhesión y compromiso organizacionales. 
Por todo lo anterior, es posible concluir que los cambios laborales y la respuesta corporativa frente a la pandemia generada por el COVID-19 han impactado muy positivamente en la calidad de vida laboral y, consecuentemente, en el desempeño laboral de la empresa del sector eléctrico colombiano motivo de estudio, de modo que se incrementan, además, los niveles de productividad y compromiso como dimensiones de la variable dependiente tratada -desempeño-.

Frente al objetivo general de este estudio que es examinar la relación y el efecto de la calidad de vida laboral (CVL) sobre el desempeño laboral bajo un contexto generado por la pandemia del COVID-19 en una organización del sector eléctrico colombiano, es posible ultimar que se establece una relación muy alta $-r=0,913-$ entre la variable independiente calidad de vida laboral y la dependiente desempeño, con un coeficiente de determinación $R^{2}=0,834$.

Por tanto, es factible concluir que al conocer la variable independiente calidad de vida es viable predecir en un $83 \%$ la variable dependiente desempeño laboral y este estudio ha sustentado esta relación, pues el 100 \% de las personas encuestadas se siente motivado y el $96 \%$ con una percepción alta o muy alta de desempeño laboral, teniendo en cuenta que todo esto sucede bajo un entorno nuevo y desconocido como lo es esta pandemia y todas sus ramificaciones.

Conjuntamente se han establecido relaciones de moderadas a fuertes $-r=0,892$ y $r=0,631-$ entre las dos dimensiones de la variable independiente calidad de vida laboral y la variable dependiente desempeño. Se establece de esta forma soportes empíricos con la teoría de Burke y Deszca (1982) —condiciones laborales, relaciones humanas y participación del colaborador frente a situaciones que lo afectan-.

Los resultados pueden contrastarse con los obtenidos por Vallejo-Calderón (2016) y Herrera-Díaz (2018), a pesar de que en sus estudios obtienen una relación de $-r=0,383$ y $r$ = 0,501-, respectivamente, entre calidad de vida y desempeño laboral. Entre los hallazgos más importantes de este estudio se encuentra que la organización investigada, a pesar del 
marco establecido por la pandemia, ha sabido involucrar al colaborador con una mayor autogestión para que su adaptación a las nuevas condiciones laborales de trabajo en casa sea más rápida y cómoda, impactando directamente estos cambios en la calidad de vida, así como en la productividad y el compromiso organizacionales (Pedraza-Melo, 2020; Ortega-Valencia, 2020).

En este mismo sentido, el constaste ajuste de la estructura empresarial centrada en las personas y sus necesidades (Pedraza et al., 2017) ha hecho que el colaborador tenga un papel protagonista utilizando al talento de forma activa, de manera que da, además, autonomía al empleado con énfasis en la igualdad y la automotivación (Auzero, 2017; Fajardo-García, 2018).

En cuanto a las limitaciones encontradas, han sido básicamente temporales, pues un estudio longitudinal, en lugar de transversal, hubiera proporcionado más información relevante a la organización motivo de análisis, además de la falta de disponibilidad del personal clave para emprender una investigación mixta.

En fin, esta investigación abre el camino a otros estudios vinculados con el desempeño laboral, como, por ejemplo, de qué manera la motivación bajo un entorno de pandemia generada por el COVID-19 se ve afectada e impacta en la productividad y el compromiso organizacionales. En este momento todos los estudios que puedan hacerse tendrán una variable extraña que influirá en los resultados finales, pues un escenario como el que se vive actualmente, tan disruptivo, cambiante y aún desconocido, golpea a la mayoría de los sectores y tendrá, seguramente, repercusiones económicas y sociales durante años. 


\section{Referencias}

Abarbanel, H.; Allaire, T.; Firsirotu, M.; Hobbs, B.; Poupart, R.; Simard (1992). Cultura organizacional. Bogotá: Legis.

Alarcón-Condori, Y. M.; Astuñague-Gonzales, J. V. (2018). Calidad de vida laboral y desempeño del profesional de enfermería. Hospital Goyeneche. Arequipa-2017 (Tesis de grado), Universidad Nacional de San Agustín. Arequipa, Perú. Recuperado de https://bit.ly/3GrMyOQ

Albalate, J. J. (2001). Las restricciones a la participación de los trabajadores en las organizaciones empresariales. Papers: Revista de Sociología, 65, 81-107. https://doi.org/10.5565/rev/papers/v65n0.1707

Aldana-Peña, J. (2013). Compromiso laboral de los trabajadores del área central de una institución bancaria que opera en la ciudad de Guatemala, según sexo (Tesis doctoral). Universidad Rafael Landívar. Guatemala de La Asunción, Guatemala. Recuperado de https://bit.ly/3MHC7sz

Alonso, S.; Volkens, A.; Gómez, B. (2012). Análisis de contenido de textos políticos. Un enfoque cuantitativo. Madrid: Editorial CIS.

Altena, E.; Baglioni, C.; Espie, C. A.; Ellis, J.; Gavriloff, D.; Holzinger, B.; Riemann, D. (2020). Dealing with sleep problems during home confinement due to the COVID-19 outbreak: practical recommendations from a task force of the European CBT-I Academy. Journal off Sleep Research, 29(4), e13052. D0I: https://doi.org/10.1111/jsr.13052

Anderson, D. R.; Sweeney, D. J.; Williams, T. A.; Roa, M. D. C. H.; Álvarez, T. L. (2001). Estadística para administración y economía (N.o 311 A54Y). Stamford: International Thomson.

Andrews, J. (1977). Shells and shores of Texas. Austin: University of Texas Press.

Aspiazu, E. (2017). Las condiciones laborales de las y los enfermeros en Argentina: entre la profesionalización y la precariedad del cuidado en la salud. Trabajo y sociedad, (28), 11-35.

Auzero, G. (2017). Los mecanismos de participación de los trabajadores en la gestión de la empresa en Francia. Documentación Laboral, (109), 71-80. Recuperado de https://bit.ly/3vQkZtC

Bastidas-Herrera, I. A.; Albarracín-Orellana, V. M. (2020). Satisfacción laboral y desempeño de los empleados de la empresa «Llermat Súper Pollo» (Tesis de grado), Universidad Técnica de Cotopaxi. Latacunga, Ecuador. Recuperado de https://bit.ly/3Bll6yB

Bird, A.; Beechler, S. (1995). Links between business strategy and human resource management strategy in US-based Japanese subsidiaries: an empirical investigation. Journal of International Business Studies, 26(1), 23-46. DOI: https://doi.org/10.1057/palgrave.jibs.8490164

Bogdan, R.; Taylor, S. J. (1990). Looking at the bright side: a positive approach to qualitative policy and evaluation research. Qualitative Sociology, 13(2), 183-192. DOI: https://doi.org/10.1007/BF00989686 
Borrero-Caldas, S.; Ossa-Flórez, G. A.; Tascón-Durán, G. A. (2008). Revisión meta-analítica de la relación entre liderazgo carismático y desempeño organizacional. Cuadernos de Administración, (39), 125-135. DOI: https://doi.org/10.25100/cdea.v24i39.386

Brito, I. (2020). Productividad laboral del talento humano: criterios a considerar en las fundaciones de intervención social de Colombia. Consensus, 4(3), 69-90. Recuperado de https://bit.ly/3nAay9R

Burke, R. J.; Deszca, E. (1982). Preferred organizational climates of Type A individuals. Journal off Vocational Behavior, 21(1), 50-59. DOI: https://doi.org/10.1016/0001-8791(82)90052-5

Caballero-Pedraza, I. M.; Contreras-Torres, F.; Vega-Chávez, E. P. V.; Gómez-Shaikh, J. J. G. (2017). Síndrome de burnout y calidad de vida laboral en el personal asistencial de una institución de salud en Bogotá. Informes psicológicos, 17(1), 87-105. DOI: https://doi.org/10.18566/infpsic.v17n1a05

Cadena-Iñiguez, P.; Rendón-Medel, R.; Aguilar-Ávila, J.; Salinas-Cruz, E.; Cruz-Morales, F. del R. de la; Sangerman-Jarquín, D. (2017). Métodos cuantitativos, métodos cualitativos o su combinación en la investigación: un acercamiento en las ciencias sociales. Revista Mexicana de Ciencias Agrícolas, 8(7), 1603-1617. DOI: https://doi.org/10.29312/remexca.v8i7.515

Calderón-Hernández, G.; Álvarez-Giraldo, C. M.; Naranjo-Valencia, J. C. (2010). Estrategia competitiva y desempeño organizacional en empresas industriales colombianas. Innovar. Revista de Ciencias Administrativas y Sociales, 20(38), 13-26.

Cantillo-Padrón, J. C. (2013). Incidencia de la cultura organizacional en el desempeño. Económicas CUC, 34(1), 131-152. Recuperado de https://bit.ly/3mlCwH3

Chenet-Zuta, M. E.; Arévalo-Quijano, J. C.; Palma-Alvino, F. (2017). Identidad cultural y desempeño docente en instituciones educativas. Opción: Revista de Ciencias Humanas y Sociales, (84), 292322.

Chiavenato, I. (2010). Administração de vendas. São Paulo: Elsevier.

Cohen, E.; Franco, R. (2000). Evaluación de proyectos sociales. Ciudad de México: Siglo XXI.

Cramton, C. D.; Orvis, K. L.; Wilson, J. M. (2007). Situation invisibility and attribution in distributed collaborations. Journal of Management, 33(4), 525-546. DOI: https://doi.org/10.1177/0149206307302549

Cruz-Ortiz, V.; Salanova, M.; Martínez, I. M. (2013). Liderazgo transformacional y desempeño grupal: unidos por el engagement grupal. Revista de Psicología Social, 28(2), 183-196. DOI: https://doi.org/10.1174/021347413806196762

Cruz-Velazco, J. E. (2018). La calidad de vida laboral y el estudio del recurso humano: una reflexión sobre su relación con las variables organizacionales. Pensamiento \& Gestión, (45), 58-81. DOI: https://doi.org/10.14482/pege.45.10617 
Cunha, J. A. C.; Corrêa, H. L. (2013). Avaliação de desempenho organizacional: um estudo aplicado em hospitais filantrópicos. Revista de Administração de Empresas, 53(5), 485-499. DOI: https://doi.org/10.1590/S0034-75902013000500006

Daft, R. L.; Steers, R. M. (1992). El comportamiento del individuo y de los grupos humanos. Ciudad de México: Grupo Noriega Editores.

Davies, H. T. O.; Mannion, R.; Jacobs, R.; Powell, A. E.; Marshall, M. N. (2007). Exploring the relationship between senior management team culture and hospital performance. Medical Care Research and Review, 64(1), 46-65. DOI: https://doi.org/10.1177/1077558706296240

de Carrasquel, S. R. (2016). ¿Para qué se estudia la calidad de vida laboral? Revista Interamericana de Psicología Ocupacional, 17(1), 34-53. Recuperado de https://bit.ly/3Cl01nj

Díaz-Pendás, H. (2003). José Martí. El sentido del compromiso. Educación La Habana, (108), 2-4.

Dodgson, M. (1993). Organizational learning: a review off some literatures. Organization Studies, 14(3), 375-394. DOI: https://doi.org/10.1177/017084069301400303

Doran, M. S.; Haddad, K. M.; Chow, C. W. (2004). The relationship between corporate culture and performance in Bahrain hotels: findings and management implications. International Journal off Hospitality \& Tourism Administration, 4(3), 65-80. DOI: https://doi.org/10.1300/J149v04n03 04

Easterby-Smith, M.; Crossan, M.; Nicolini, D. (2000). Organizational learning: debates past, present and future. Journal off Management Studies, 37(6), 783-796. DOI: https://doi.org/10.1111/1467-6486.00203

Elguedas-Hernández, E. I. (2017). Influencia del liderazgo en el desempeño laboral del personal de la empresa Peruvian Andean Trout SAC Distrito de SJM, año 2017 (Tesis licenciatura en administración). Universidad César Vallejo. Lima, Perú.

Fabila-Echauri, A. M.; Minami, H.; Izquierdo-Sandoval, M. J. (2012). La Escala de Likert en la evaluación docente: acercamiento a sus características y principios metodológicos. Perspectivas docentes, (50), 31-40.

Fajardo-García, G. (2018). Participación de los trabajadores en la empresa y sociedades laborales. Barcelona: Tirant lo Blanch.

Fiol, C. M.; Lyles, M. A. (1985). Organizational learning. Academy off Management Review, 10(4), 803813. DOI: https://doi.org/10.5465/amr.1985.4279103

Galarza-Torres, S. P. (2019). Liderazgo y desempeño en las cooperativas de ahorro y crédito ecuatorianas: un acercamiento desde las contribuciones teóricas clásicas y contemporáneas (Tesis doctoral). Universidad Nacional de La Plata. Buenos Aires, Argentina. Recuperado de https://bit.ly/3En2WhP 
Galicia-Alarcón, L. A.; Balderrama-Trápaga, J. A.; Edel-Navarro, R. (2017). Validez de contenido por juicio de expertos: propuesta de una herramienta virtual. Apertura, 9(2), 42-53. DOI: https://doi.org/10.32870/ap.v9n2.993

García-Cán, J. P. (2018). Programa para la detección, prevención y reducción de factores que disminuyen la eficiencia, eficacia y efectividad en el área de producción de una empresa industrial (Tesis doctoral). Universidad de San Carlos de Guatemala. Guatemala. Recuperado de https://bit.ly/3EruLWl

Gelade, G.; Gilbert, P. (2003). Work climate and organizational effectiveness: the application off data envelopment analysis in organizational research. Organizational Research Methods, 6(4), 482501. DOI: https://doi.org/10.1177/1094428103257364

Gilley, J. W.; Dean, P.; Bierema, L. (2001). Philosophy and practice of organizational learning, performance and change. Nueva York: Perseus Books.

Gómez-Córdova, D. (2019). Relación de la evaluación de desempeño y la productividad laboral en la empresa Supermercados Peruanos S.A. sucursal Plaza Vea Cajamarca-2018 (Tesis de grado). Universidad Privada del Norte. Bogotá, Colombia. Recuperado de http://hdl.handle.net/11537/21312

Gómez-Rivera, M. A. (2019). Optimización de las condiciones laborales y su influencia en el clima laboral de los trabajadores en un proyecto de edificación mediano en Lima, periodo junio 2018 a junio 2019 (Tesis maestría). Universidad de Ricardo Palma. Lima, Perú. Recuperado de https://bit.ly/3nyY5U2

Goodman-Casanova, J. M.; Dura-Pérez, E.; Guzmán-Parra, J.; Cuesta-Vargas, A.; Mayoral-Cleries, F. (2020). Telehealth home support during COVID-19 confinement for community-dwelling older adults with mild cognitive impairment or mild dementia: survey study. Journal of Medical Internet Research, 22(5), e19434. DOI: https://doi.org/10.2196/19434

Graţiela-Florentina, M. (2019). Acerca del derecho de participación de los trabajadores en la unión europea. Revue Européenne du Droit Social, 2(43), 88-97.

Hawkley L. C.; Capitanio, J. P. (2015). Perceived social isolation, evolutionary fitness and health outcomes: a lifespan approach. Philosophical Transactions of the Royal Society B, 370, 1-12. DOI: https://doi.org/10.1098/rstb.2014.0114

Herrera-Díaz, D. S. (2018). Calidad de vida, clima y desempeño laboral del profesional de enfermería del Hospital Nacional Daniel Alcides Carrión, Callao, 2016 (Tesis de maestría). Universidad César Vallejo. Lima, Perú.

Hitt, M. A.; Ireland, D.; Hoskisson, R. E. (2008). Administración estratégica: competitividad y globalización: conceptos y casos. Texas: Cengage Learning.

Jaik-Dipp, A.; Tena-Flores, J. A.; Villanueva-Gutiérrez, R. (2010). Satisfacción Laboral y compromiso institucional de los docentes de posgrados. Diálogos Educativos, (19), 119-130. 
Jenkins, J. C. (1983). Resource mobilization theory and the study of social movements. Annual Review of Sociology, 9, 527-553. DOI: https://doi.org/10.1146/annurev.so.09.080183.002523

Kamoche, K.; Mueller, F. (1998). Human resource management and the appropriation learning perspective. Human Relations, 51(8), 1033-1060. DOI: https://doi.org/10.1023/A:1016959813484

Kotha, S.; Vadlamani, B. L. (1995). Assessing generic strategies: an empirical investigation of two competing typologies in discrete manufacturing industries. Strategic Management Journal, 16(1), 75-83. DOI: https://doi.org/10.1002/smj.4250160108

Kruse, K. M. (2013). White flight: Atlanta and the making of modern conservatism (Vol. 89). Princeton: Princeton University Press.

Leiva-Gómez, S.; Mansilla-Agüero, M. Á.; Comelin-Fornes, A. (2017). Condiciones laborales de migrantes bolivianas que realizan trabajo de cuidado en Iquique. Si Somos Americanos, 17(1), 11-37. DOI: https://doi.org/10.4067/S0719-09482017000100011

León-Suarez, L. (2019). Compromiso organizacional y su relación con la productividad laboral en la Municipalidad Provincial de San Martín, Tarapoto en el año 2016 (Tesis de grado). Universidad Nacional de San Martín. Tarapoto, Perú. Recuperado de https://bit.ly/2XOGf6q

Lockheed, M. E.; Hanushek, E. A. (1994). Concepts of educational efficiency and effectiveness. Washington: World Bank.

Luciano, S. (2016). Optimización de las condiciones laborales y motivacionales (Tesis doctoral). Universidad Siglo 21. Córdoba, Argentina. Recuperado de https://bit.ly/3GEiHTF

Lumbreras-Guzmán, M.; Hernández-Vicente, I. A.; Méndez-Hernández, P.; Dosamantes-Carrasco, L. D.; Cervantes-Rodríguez, M.; García-Elizalde, A.; Cortez-Yacila, H. M. (2019). Influencia de la calidad de vida laboral sobre el desempeño de trabajadores de hospitales públicos de México: una visión desde la gestión directiva. Salud Pública de México, 62(1), 87-95. DOI: https://doi.org/10.21149/10247

Mallo, C.; Merlo, J. (1995). Control de gestión y control presupuestario. Madrid: McGraw-Hill.

Martínez-Avella, M. E. (2010). Relaciones entre cultura y desempeño organizacional en una muestra de empresas colombianas: reflexiones sobre la utilización del modelo de Denison. Cuadernos de Administración, 23(40), 163-191. Recuperado de https://bit.ly/317Rto2

Martínez-Pérez, J. F. (2005). Estrategia medioambiental de la empresa y rendimiento. El rol intermedio del aprendizaje organizativo: una aplicación a las industrias minerales (Tesis doctoral). Universitat de València. Valencia, España. Recuperado de https://bit.ly/3jJPzil

Mayo, E. (1949). The social problems of an industrial civilization. London: Routledge. 
Munuera-Alemán, J.; Rodríguez-Escudero, A. (2007). Estrategias de marketing: un enfoque basado en el proceso de dirección. Madrid: Esic Editorial.

Murillo-García, F.; Montaño-Ulloa, P. Y. (2018). Condiciones laborales de egresados de Instituciones de Educación Superior en México. Revista Electrónica de Investigación Educativa, 20(3), 5668. DOI: https://doi.org/10.24320/redie.2018.20.3.1644

Nares-González, M. L.; García-Nares, P. D. C.; Arvizu-López, B. A.; Olimón-Robles, A. Y. (2014). Las relaciones humanas en la universidad y el impacto en la calidad educativa. Revista Iberoamericana de Producción Académica y Gestión Educativa, 1(1) 1-17. Recuperado de https://bit.ly/3vQJTt3

Ortega-Valencia, Á. G. (2020). La satisfacción laboral en el desempeño individual de Instituciones Públicas Emthymós, Revista de Estudios Empresariales, 1(2), 147-157. Recuperado de https://bit.ly/3mkFGLh

Pedraza- Melo, N. A. (2020). Satisfacción laboral y compromiso organizacional del capital humano en el desempeño en instituciones de educación superior. Ride: Revista Iberoamericana para la Investigación y el Desarrollo Educativo, 10(20), e051. DOI: https://doi.org/10.23913/ride.v10i20.595

Pérez-Zapata, J.; Costa-Ramírez, J. A. (2009). Medición y validación del como resultado de acciones de aprendizaje. Revista Ciencias Estratégicas, 17(22), 251-272.

Pichón-Castillo, C. M.; Vega-Muñoz, M. N. (2020). El trabajo en casa, medida de emergencia ante la situación de covid-19 en Barranquilla que vulnera las condiciones de trabajo del empleado (Ensayo instituto de posgrados). Universidad Simón Bolívar. Barranquilla, Colombia. Recuperado de https://bit.ly/3bdQQLs

Porter, M. (1980). Estrategia competitiva: técnicas para el análisis de la empresa y sus competidores. Madrid: Pirámide.

Powers, T. L.; Hahn, W. (2004). Critical competitive methods, generic strategies, and firm performance. International Journal of Bank Marketing, 22(1), 43-64. DOI: https://doi.org/10.1108/02652320410514924

Quintanilla, I. (1987). La participación en las organizaciones: fundamentos teóricos y conceptuales. Valencia: Promolibro.

Quinto-Minda, S. P. (2018). Calidad de vida y su incidencia en el desempeño laboral (Tesis de grado). Universidad Estatal de Milagro. Milagro, Ecuador.

Reis-Neto, M. T.; Araújo, R. N. de; Avelar-Ferreira, C. A. (2019). Leadership theories and individual performance. Pensamiento \& Gestión, 47, 148-179. Recuperado de https://bit.ly/3nAAToj 
Rico, R.; Cohen, S. G.; Gil, F. (2006). Efectos de la interdependencia de tarea y la sincronía en las tecnologías de comunicación sobre el rendimiento de los equipos virtuales de trabajo. Psicothema, 18(4), 743-749. Recuperado de https://bit.ly/3jGtOkM

Rincón, Y.; Zambrano, E. (2008). Equipos de trabajo virtual: los desafíos del trabajo compartido a distancia. Negotium: Revista de Ciencias Gerenciales, 4(11), 104-119. Recuperado de https://bit.ly/3vQJXsN

Rojas, M.; Jaimes, L.; Valencia, M. (2018). Efectividad, eficacia y eficiencia en equipos de trabajo. Revista Espacios, 39(6), 11. Recuperado de https://bit.ly/3mmD3bU

Rothwell, W. J.; Hohne, C. K.; King, S. B. (2012). Human performance improvement. Londres: Routledge. DOI: https://doi.org/10.4324/9780080475424

Schein, E. H. (1990). Organizational culture. American Psychologist, 45(2), 109-119. DOI: https://doi.org/10.1037/0003-066X.45.2.109

Shaffer, M. A.; Harrison, D. A.; Gilley, K. M.; Luk, D. M. (2001). Struggling for balance amid turbulence on international assignments: work-family conflict, support and commitment. Journal of Management, 27(1), 99-121. DOI: https://doi.org/10.1177/014920630102700106

Shamir, B.; House, R. J.; Arthur, M. B. (1993). The motivational effects of charismatic leadership: a self-concept based theory. Organization Science, 4(4), 577-594. DOI: https://doi.org/10.1287/orsc.4.4.577

Slimani, M.; Paravlic, A.; Mbarek, F.; Bragazzi, N. L.; Tod, D. (2020). The relationship between physical activity and quality of life during the confinement induced by COVID-19 outbreak: a pilot study in Tunisia. Frontiers in psychology, 11, 1882. DOI: https://doi.org/10.3389/fpsyg.2020.01882

Soto-Rodríguez, F. C. M. (2019). Compromiso organizacional y el desempeño del personal administrativo de la ONG Ides Sican-Ferreñafe 2019 (Tesis de grado). Universidad Señor de Sipán. Pimentel, Perú. Recuperado de https://bit.ly/3GqXbl5

Stolovitch, H. D.; Keeps, E. J. (1992). Handbook off human performance technology: a comprehensive guide for analyzing and solving performance problems in organizations. San Francisco: Pfeiffer. DOI: https://doi.org/10.1002/pfi.4170310205

Suescún-Carrero, S.; Sarmiento, G.; Álvarez, L.; Lugo, M. (2016). Calidad de vida laboral en trabajadores de una Empresa Social del Estado de Tunja, Colombia. Revista Médica de Risaralda, 22(1), 14-17. DOI: https://doi.org/10.22517/25395203.13631

Tejedor-Tejedor, F. J. (2000). El diseño y los diseños en la evaluación de programas. Revista de Investigación Educativa, 18(2), 319-339. Recuperado de https://bit.ly/3El2bWu

Urcola-Tellería, J. L.; Urcola-Martiarena, N. (2017). Dirección participativa: cómo potenciar la participación de los trabajadores; un reto para todos. Madrid: ESIC Editorial. 
Vallejo-Calderón, M. (2016). Calidad de vida profesional, estrés y desempeño laboral en profesionales de enfermería del Hospital de Chancay, 2016 (Tesis de maestría). Universidad César Vallejo. Lima, Perú.

Ventura-León, J. L. (2018). ¿Es el final del alfa de Cronbach? Adicciones, 31(1), 80-81. DOI: https://doi.org/10.20882/adicciones.1037

Villatoro-Garza, J. E. (2013). Herramientas de aprendizaje y productividad: para construir las competencias básicas del crecimiento integral. Barcelona: Palibrio.

Williams, R. (2001). Cultura i sociedad: 1780-1950: de Coleridge a Orwell. Ciudad de México: Nueva Visión. 